\title{
The Impact of Sports on Athletic Performance
}

\author{
Amir Torkashvand $^{1}$ \\ ${ }^{1}$ Masters degree student of aba non-profit university, Iran \\ Correspondence: Amir Torkashvand, Masters degree student of aba non-profit university, Iran.
}

Received: February 22, 2016

Accepted: March 20, 2016

Online Published: March 22, 2016

doi:10.5539/mas.v10n6p21

URL: http://dx.doi.org/10.5539/mas.v10n6p21

\begin{abstract}
This study seeks to influence environment sports on the performance of athletes. Applied research is a descriptive survey. The population consisted of high-level of athletes in martial disciplines in Tehran (3 sports gym) were estimated at around 158 people. 113 athletes have been invited to respond to the questionnaire that they use randomly chosen sample of the population by Cochran formula. A questionnaire was used for data collection. The questionnaire consists of 3 parts. The first part included demographic information and the second part of the questionnaire contains 12 questions, including questions of appearance and the third part is consist of the standard questionnaire strategic performance of Thomas. Relaiability of questionnaire is achived with experts and stability of it was 0,966 by using of Cronbach's alpha coefficient in e SPSS software. The results show that the apparent and qualitative factors are directly affecting the performance of athletes.
\end{abstract}

Keywords: external factors, qualitative factors, performance

\section{Introduction}

Environmental factors play important role in the health of athletes and their ability to function. Necessary conditions are provided to maintain the health of athletes so are identified the factors that reduce the ability and athletic performance and presentation appropriate solutions to be adopted to deal with it. To set health and compatibility issues that cause athlete in environments other than the original location and the athlete standing are defined as complies with environmental factors. Environmental factors are including a wide range of color coverage, the grass condition for athlete, the salon, light, sound and temperature to important factors such as heat, cold, light, sun, altitude, humidity, rain and wind (site of Iran Pezeshk, 2015). In recent years, educators and psychologists dramatically use of mental skills and techniques to improve the performance of athletes and the control and mitigation of environmental factors the negative shape (Neil, 2006). The present study is to analyze the impact of the sport on their athletic performance.

\section{Research Literature}

No doubt, today, around the world, sport is a unique phenomenon due to its efficient that it can be used in many categories including the categories of cultural, social, economic and so achieved significant growth. The effects of sports on individuals, families and society in many cases are quite special and unique that other phenomenon is not visible. Consequently, the role of exercise and sport centers in the modern age is as a critical factor for tourism and leisure sports for citizen (Jones, 2002).

Many factors can affect the performance of athletes in sports that include:

External factors: color, sound, light, green space

Qualitative factors: including temperature and humidity, ventilation, heating, cooling, standards related fields

\section{Evaluation of Apparent Factors}

\section{Color}

Often people are inattentive to their surroundings. For years, in developed countries have been recignized the impact of color on mood and energy levels and so the quality of life and environment, as well as in the field of research and has been done a lot of research. However, extensive progress has been made in this field. The science has the root for several thousand years. Based on archaeological excavations and research in this field, following the philosophy of the use of certain colors in specific situations discover that the indigenous tribes of America and Latin America have used special colors. For example, it took a war between tribes to use the red 
color that was obtained from clay that was found in those areas to create fear and terror in opponent. Also in some religious ceremonies specific were used the color that was derived from a type of sludge (as black) and a mineral soil (in white) and were combined them and get black face and body white. In some remnants of past civilizations have been realized the philosophy of the images. Nowadays it's so interesting that even in military fields has been used a lot of research in this field. For example, America's Army has been a lot of research on the type of paint and the impact on the conduct of soldiers. These studies prove that green have a positive impact on the kinds of decisions in necessary situation. Ironically, during the investigation have been found red color has adverse effects of violence of soldiers. Free fields as: Double Full Contact, Kickboxing, Full Contact and others have used certain colors. If you're a coach or even students bring up this issue with the quality of your workouts with the changes in the environment that it will maximize your workout. If you work in an environment where there is the ambient light and space as sufficiently, using warm colors like orange or bright red give excitement and vitality to the students. If you practice in a limited area with low ceilings and many columns you can cover columns with proper insulation for example, you can consider multi-layered foam on the walls with bright red-and-white and color scheme and must be there is sufficient light in the environment that are not causes headaches and visual stimulation in athletes.

The field is so wide that is consider as a career in academic research and research-oriented fields of color psychology in doctoral levels in advanced countries.

Color is very important in the training of an athlete. If an athlete practice as professional this need is much more sensible. However, because too much light or due to low light. Practice in dim light can cause apprehension, anxiety, as well as creating a sense of purpose and sometimes despair, so avoid it strongly. The effect of red, orange and yellow has been proven to increase efficiency of training. The only thing that is worth to mention is that the combination of colors is very important in an environment. Never put together do not use bright colors and dark. It causes long-term mental stress. Do not use the same cool colors. In combat even colors in the environment should have a positive impact on the excitement and sportsmanship?

\section{Sound}

Most sound is caused by the sports hall of the players and the ball collsion with floor. Very smooth and polished concrete floor is causing intense reflection of sound and contrary softer floor is importand to soundless. Noise caused by the movement of the floor surface is often raised as a problem by users. The problem is from two regions. The noise caused by audio devices such as radio and television, music, etc. The second type of noise caused by severe blows, like walking, running, falling objects and leg kicks. To resolve this problem usually are used two types of insulation. Some companies also have insulation with two types of abilities that help in reducing the primary and secondary sounds. The insulating panels are to be placed on a flat surface and the floors. This usually thick insulation and a lot of weight and are subject to change and different spaces in the area of course, this type of insulation for roofs are also used if both simultaneously reducing sound transmission for the first type as radio and television, music, etc and it will be more effective for the second type of sound as feet, falling objects, etc. Insulated panel system (acoustics) is used for sound reduction in buildings such as sound studios, lecture theaters, music rooms, offices, meeting rooms, class courses, cinemas, negotiation and interview rooms and sports halls. The panel has a range of different colors. This insulation must be durable and visually beautiful against fire. They should be used to the sounds in the environment.

\section{Light}

The projected light in the stadium is created a situation in which a particular exercise can be done properly and safely. Light design should be such that the speed of play and the actual size of each object are fully visible. It also has a beautiful and comfortable enough for exercise and the audience. For all sports right level of light is needed based on international standards. The main effects of light and shadow, which is the main and lower levels arise should be appropriate to set up a three-dimensional objects and clear visible (HM site, 2015). Note that environment full of colors do not stimulate the optic nerve and causes the pressure on the athlete nerves. The harmony of color combinations must be fit together and beautiful. Flooring and wall color should complement rather than contradict each other. During exercise, athletes should try to make use of light-colored clothing that can be thinking and buoyancy. On the wall and in a great frame used martial sentences as great inspiration during exercise until causes athlete's mind engaging with the broader content of the training.

\section{Green space}

The environment in which we live is affecting on all our efforts and physical activity so we can not ignore the effects of the environment on human life cycle. Therefore, we must accept the fact that the environment plays an important role in all present interactions. Modern man rather than the use of physical force and activity of our 
work are done them by various machines. Our ancestors had to try to do most of their daily activities and physical activity, and this has helped their physical and mental health of the human body. While the devices are made by active and do more will be added on them. The desire to promote sport and participation in economic and cultural development of the region can be considered as justification for changes in natural areas according to the Environmental Protection Mountains, rivers, forests that should have priority over mere economic reasons (Civilica, 2015).

\section{Check the qualitative factors}

\section{Humidity}

Humidity in the halls, swimming pools and showers is a very important factor. Experts believe that the air indoors should not be too dry as cause's skin irritation, breathing hard and static electricity. In the winter months the problem is a bit more serious because the heating instruments are on and mix with air and so it reduce water particles suspended in air. Water particles are transported by air and are effective on human health. Very high humidity can cause decay that it is more effective in humid areas (Marandi, 2009).

\section{Air conditioner}

Proper ventilation prevents the building from destruction. When the humidity level in indoor spaces is not appropriate, mildew and fungi growth and ceilings and walls in the fall and brightness of metal, destroyed windows and doors and it would oxidize quickly that so they endanger the health of the building. If the humidity is adequately controlled, less downtime and maintenance costs are greatly reduced. Easily is one of the biggest factors that increasing the use of indoor venues. That has a lot of suspended particles in the breathe air that is too cold or breathing are problematic. Ventilation devices control temperature, humidity and dry indoor air, convenient and fun sport environment for their users. If air conditioning has good quality so prevents the energy waste through evaporation and prevents access to the outside air (Marandi, 2009). Clinical cases of cold injuries include heat swelling, spasms of the hands and feet, caused by heat syncope, heat cramps, heat exhaustion and heat stroke (HMS site, 2015).

When the body can not excrete excess heat production heat stroke is happen. Environmental factors such as high temperature, severe drought, not windy weather, intense activity, wear clothing that keeps the heat and dehydration (dehydration), are included in the development of heat stroke. Initial symptoms include excessive sweating, headache, nausea, dizziness, increased pulmonary ventilation and impaired consciousness; there is sometimes shock by increasing the heart rate. Breathing is shallow and harsh and a little difficult sometimes vomiting material into the respiratory tract. Athletes feel warm or hot, and are hight the core body temperature. Rectal temperature is usually " above $41^{\circ} \mathrm{C}$. Sometimes there is transpiration. High index of suspicion is necessary to diagnose heatstroke dealing with athletes overheated if heat exhaustion is not treated in a correct way, there is the risk of irreversible damage to the brain, kidney, liver and adrenal glands, and in some cases may even cause the death of the athlete (HM site, 2015).

\section{Cooling system}

Body temperature is with little fluctuation around 37 Celsius degrees. To maintain normal range temperature must be equal to the rate of heat production and absorption. Absorption of heat can be achieved by radiation from the sun or other hot objects. In the short-term and hard training increase the heat 16 to 10 times the base amount. Heat methods include: Radiation or radiation, conduction, evaporation, evaporation subtle, loss of water from the respiratory tract, sweating. Some studies show that women are more vulnerable to heat but in this study, most men and women with high physical fitness and physical fitness are low compared with each other. Since the efficiency of the cardiovascular system is considered to implement the most important physiological tolerance of exercise in the heat, further research was conducted in which men and women were compared with the efficiency of the heart and so arteries were similar. The study of heat tolerance was equally represented between men and women (HM site, 2015).

\section{Fields Standards}

Due to increasing young labor force and taking into account the rest of the people, their needs and health (physical and mental) and leisure, to engage in sport activities that meet this need, as well as the need to achieve high quality medals at the continental sporting competitions and world and Olympic, which increased national pride and create a national matter, and as part of the country's policies in the 20 years that has been approved by the authorities and competitions in sports international of the areas identified in this way enables our country to the world in various fields. Attention to various aspects that are related to exercise programs, including trainers and referees and experts and educational programs, training and athletic competitions, including the 
establishment of appropriate facilities that are double all of standards. Obviously, in this regard is very significant a deep respect and responsible to build sports spaces, since a standard and safe sport facilities for athletes' health can be essantial the promotion of skills and favorable view of the training, during exercise and compete (Internal and external). Whilethere is the debate on this issue.

For this study we can say that the facilities construction is very important for laws and regulations of various sporting disciplines and standard safety conditions in terms of sports fields, equipment and other physical factors such as light, heat, air circulation and coordination to bring the activities of the Engineering Services standards of sport - recreational sport.

Table 1. Dimensions and standards for sports groung

\begin{tabular}{|c|c|c|c|c|c|}
\hline \multicolumn{6}{|c|}{ Standard for sports ground dimensions $(\mathrm{L} * \mathrm{~W} * \mathrm{H})$} \\
\hline \multirow[t]{2}{*}{ row } & \multirow[t]{2}{*}{ field } & \multicolumn{4}{|c|}{ National and international } \\
\hline & & Length & Width & Height & Comments \\
\hline 1 & Squash & 9.75 & 6.3 & 5.7 & \\
\hline 2 & Skating & 60 & 20 & & \\
\hline 3 & Badminton & $13 / 3$ & 6.1 & 9.1 & \\
\hline 4 & Bodybuilding & 4 & & & \\
\hline 5 & Basketball & 30 & 15 & 7 & \\
\hline 6 & Indoor- outdoor tennis & 23.77 & 10.97 & 9 & \\
\hline 7 & Archery (lounge) & & & & \\
\hline 8 & Shooting with firearms & 30 & 10.96 & 3 & \\
\hline 9 & Archery (outdoor) & 183 & 150 & 4 & \\
\hline 10 & Jujitsu & 10 & 10 & 7.6 & \\
\hline 11 & riding bike $333 \mathrm{~m}$ & 150 & 70 & & \\
\hline 12 & riding bike $250 \mathrm{~m}$ & 112 & 60 & & \\
\hline 13 & Indoor Track and Field $125 \mathrm{~m}$ & & & & \\
\hline 14 & Indoor Track and Field $160 \mathrm{~m}$ & 71.46 & 47.19 & 9 & \\
\hline 15 & Indoor Track and Field 200m & 91.65 & 47.18 & 9 & \\
\hline 16 & Gymnastics & 47.5 & 23 & 7.6 & \\
\hline 17 & Indoor Equitation & & 40 & 4 & \\
\hline 18 & Outdoor Equitation & 110 & 50 & & \\
\hline 19 & Bat & 238 & 174 & & \\
\hline 20 & Swordsmanship & 14 & 2 & 3.6 & \\
\hline 21 & Football & $105-110$ & $64-75$ & & \\
\hline 22 & Karate & 8 & 8 & 4.5 & \\
\hline 23 & wrestle & 12 & 12 & 7 & \\
\hline 24 & Boxing & 6.1 & 6.1 & 7.6 & \\
\hline 25 & Volleyball & 18 & 9 & 9 & \\
\hline 26 & weightlifting & 4 & 4 & 4.5 & \\
\hline 27 & Outdoor Hockey & 91 & 55 & & \\
\hline 28 & Indoor Hockey & 36 & 17 & 7.6 & \\
\hline 29 & Indoor handball & 40 & 20 & 2 & \\
\hline 30 & Outdoor handball & & & & \\
\hline 31 & Taekwondo & 12 & 12 & 4.5 & \\
\hline 32 & Ping-pong & 14 & 7 & 4.5 & \\
\hline 33 & Swimming pool of children & $16.6-20$ & 7 & $90 \mathrm{~cm}$ & \\
\hline 34 & Water Polo & $3-27.5$ & $15.5-20$ & & $\begin{array}{l}\text { Depth of } 2 \\
\mathrm{~m}\end{array}$ \\
\hline 35 & Football Floret & $38-42$ & $18-25$ & 7 & \\
\hline
\end{tabular}

\section{Background of Research}

Susan (2001) investigate the relationship between mental skills and athletic performance in their study, however she shows that the players have more confidence and use mental skills methods have better performance in critical situations. Mozafar et al. (2010) stated that blue color is the best and most popular color to the exam hall. 
It works by relaxing the reference color and a color that can reduce the level of arousal and stress in humans. According to evaluation the most research studies were about the design of sports complex. For example, the Olympic Village Lray of African Championship in 2015 which was conducted by Paris and Madrid company and sports complex urban design ((Chengzo)) was done in cooperation with the Chinese company DUO in Chengzo in China and China's national sport has been the main target that it is next to the center of sports events for people to buy and train and done various concerts and exhibitions. In the interior samples can be mention an excellent sports and cultural village in the Bushehr and like it present in Tabriz and the Olympic Village Jihad garden in Alborz province and we can mention the Tehran Olympic Village, which are serve the service.

\section{Conceptual Model}

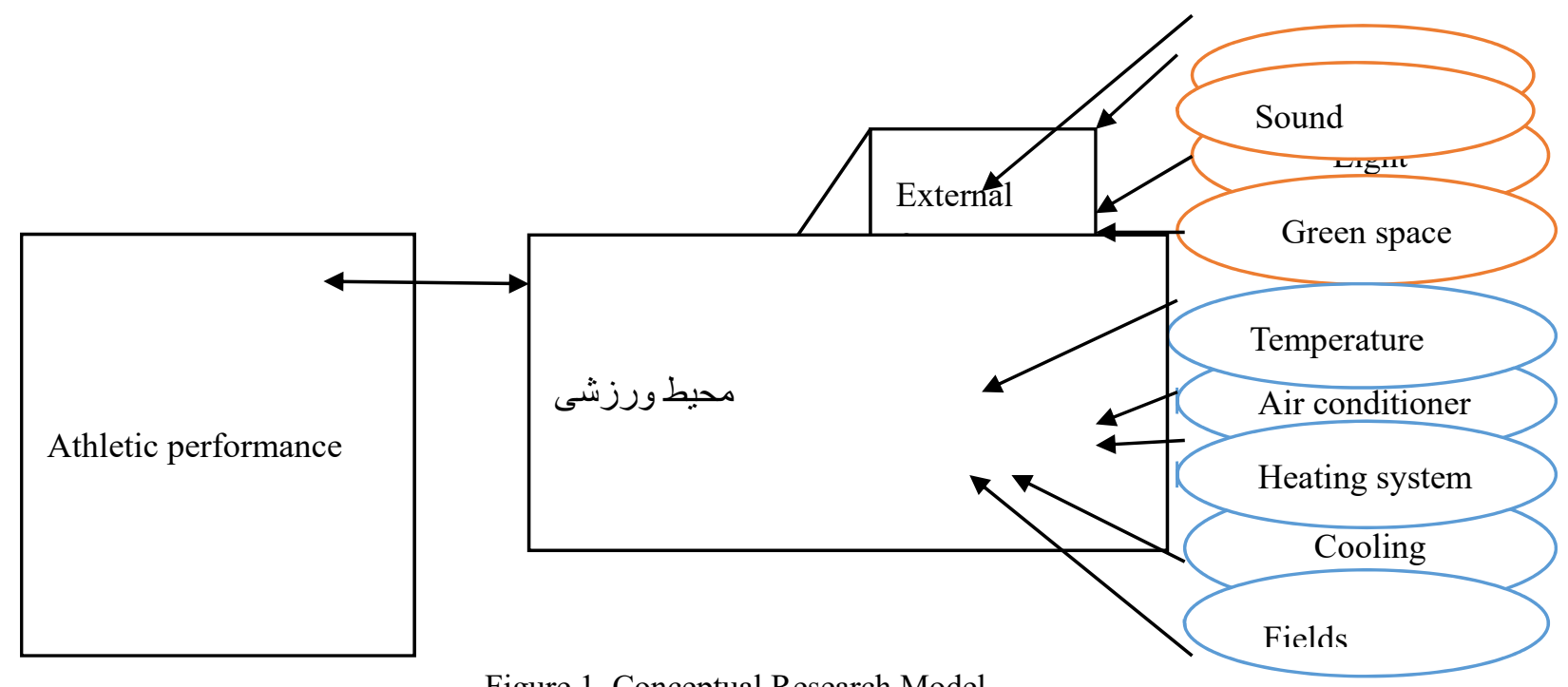

Figure 1. Conceptual Research Model

\section{Research Methodology}

Applied research is a descriptive survey. The population consisted of high-level of athletes in martial disciplines in Tehran ( 3 sports gym) were estimated at around 158 people. 113 athletes have been invited to respond to the questionnaire that they use randomly chosen sample of the population by Cochran formula.

A questionnaire was used for data collection. The questionnaire consists of 3 parts. The first part included demographic information and the second part of the questionnaire contains 12 questions, including questions of appearance and the third part is consist of the standard questionnaire strategic performance of Thomas. Relaiability of questionnaire is achived with experts and stability of it was 0,966 by using of Cronbach's alpha coefficient in e SPSS software.

\begin{tabular}{cl}
\hline Cronbach's alpha coefficient & \multicolumn{1}{c}{ Variables } \\
\hline $0 / 874$ & External factors \\
$0 / 914$ & Qualitative factors \\
$0 / 924$ & Athletic performance \\
$0 / 918$ & The reliability of the questionnaire \\
\hline
\end{tabular}

\section{Data Analysis}

Described the sample by gender 
Table 1. Sex subjects

\begin{tabular}{ccc}
\hline Percent & Frequency & variable \\
\hline 30.97 & 35 & female \\
69.03 & 78 & male \\
100 & 113 & total \\
\hline
\end{tabular}

According to Table 30.97 percent of subjects are female and and 69.03 percent are male.

\section{Described the sample according to educational level}

Table 2. Education level of subjects

\begin{tabular}{ccc}
\hline Percent & Frequency & variables \\
\hline 50.44 & 57 & Diploma and lower \\
37.16 & 42 & Graduate \\
12.40 & 14 & Master degree and more \\
100 & 113 & total \\
\hline
\end{tabular}

According to the table, $50.44 \%$ of participants have a lower degree, 37.16 percent and 12.40 percent of respondents had a graduate's degree ans master's degree and higher respectively.

\section{Described the sample by age}

Table 3. Age of subjects

\begin{tabular}{cccccc}
\hline total & More than 50 & $41-50$ & $31-40$ & $15-30$ & \\
\hline 113 & 8 & 13 & 25 & 67 & Frequency \\
100 & 7.07 & 11.50 & 22.13 & 59.30 & percent \\
\hline
\end{tabular}

59.30 percent of respondents were between 15 and 30 years, $22.13 \%$ between 31 and 40 years, $11.50 \%$ between 41 and 50 years and 7.07 percent weree aged 50 and above.

With using the Kolmogorof-Smirnof test showed that data has been abnormal distributed.

Value t-test was used to test the hypothesis. The results showed that all qualitative factors and external factors affect the performance of athletes.

\section{Friedman test}

To determine the priority of the respondents' views was used of Friedman test. SPSS output includes the following table. The following table is the average rank of each of the relevant variables.

Table 4. Ranking Factors

\begin{tabular}{cccc}
\hline priorities & Average rating & Dimension & ROW \\
\hline first & $3 / 69$ & Qualitative factors & 1 \\
second & $3 / 22$ & External factors & 2 \\
\hline
\end{tabular}

\section{Conclusion}

Demographic findings showed:

30.97 percent of subjects are female and and 69.03 percent are male.

$50.44 \%$ of participants have a lower degree, 37.16 percent and 12.40 percent of respondents had a graduate's degree ans master's degree and higher respectively.

59.30 percent of respondents were between 15 and 30 years, $22.13 \%$ between 31 and 40 years, $11.50 \%$ between 
41 and 50 years and 7.07 percent weree aged 50 and above.

The subject of study was about environmental impact on sport and athletic performance. The results showed that the appearance and quality factors affect directly on the performance of athletes. Components influencing the evolution of the quality of training an athlete in a simple form include:

- Spaciousness practice (depending on the type of sport)

- Quality of flooring, tatami mats and so on. As well as its color

- colors of athlete cloth

- type of clothing and shoes for athletes and the freedom

- use of mirrors to specific disciplines

- Suitable Ventilated place to practice

- $\quad$ Paint the walls

- Ceiling height

- The amount and quality of light

- Music playback in the environment

- The impact of form and volume of buildings

- The impact of the location plan and buildings to each other

Of course there are many cases that affect on workout routines as positive and negative effects.

\section{Recommendation}

The researchers recommended the following topics in their research:

- Factors that affecting the performance of athletes with structural equation modeling

- Pathology of athletic performance with the pattern of three ramifications doctor Ahranjani

- The impact of the internal architecture of a sports environment on athletic performance

- To analyze factors that influencing athletic performance national teams

\section{References}

Bale. J., \& Sang, J. (1996). Kenyan running: movement culture, geography and global change. Frank Cass, London.

Fakhri. R. (2008). Identification of Zobe Ahan's Economic, Social and Traffic effects on urban Environment. Physical Education and Sport Sciences Thesis.

Jimenez, D., Barko, L., Martinez, P., \& Hita, E. (1991). Visual reaction time measurements with background provided by color monitors. Journal of Optics, 22(3), 129-133.

Jones, C. (2002). Public cost for Private gain? Recent and proposed national stadium developments in the UK, and commonalities with North America. Royal Geographical Society (with theInstitute of British Geographers), 34(2), 160-170.

Mozaffar, F., \& Mahdizade, F. B. M. (2009). Analysis of the effect of exam hall color on components of students' psychological. Scientific Society of Architecture and Urban Planning, 1, 119-128.

O'Donell, B., \& Colombo, E. (2008). Simple reaction times to chromatic stimuli: Luminance and chromatic contrast. Lighting research and technology, 40, 359-371.

Quinn, M. (2005). The effect of element color on reaction time in visual search tasks. Journal of undergraduate science engineering and technology, KHA306.

Richard, N., \& Stephan, D. (2006). psychological skills usage and the copmpatitive anxity response in Rugby union. Journal of Sport Science, 5, 415-4230.

Schmidt, R. A., \& Wrisberg, C. A. (2008). Motor learning and performance: A situation-based learning approach. Champion, IL: Human Kinetics.

Susan, A. (2001). Relationship between flow self-concept and performance psychological skills and performance. Journal of applied sport Psychology, 13, 129-153. 


\section{Web References}

http://www.civilica.com/Paper-NCCS01-NCCS01_029=\%D9\%88\%D8\%B1\%D8\%B2\%D8\%B4\%D9\%88-\%D9

\%85\%D8\%AD\%DB\%8C\%D8\%B7-\%D8\%B2\%DB\%8C\%D8\%B3\%D8\%AA.html

http://www.hm63.blogfa.com/post-5.aspx

http://www.iran.pezeshk.us/archives/29957

\section{Copyrights}

Copyright for this article is retained by the author(s), with first publication rights granted to the journal.

This is an open-access article distributed under the terms and conditions of the Creative Commons Attribution license (http://creativecommons.org/licenses/by/3.0/). 